\title{
An overview of thyroid fine-needle aspiration practice in Myanmar
}

\author{
Zun Pwint Oo ${ }^{1 \wedge}$, Aung Myo Hlaing ${ }^{2}$, Khin Chaw Su Kyi ${ }^{1}$, Junya Fukuoka ${ }^{3,4}$, Andrey Bychkov ${ }^{3,4}$ \\ ${ }^{1}$ Department of Pathology, University of Medicine, Mandalay, Myanmar; ${ }^{2}$ Department of Pathology, University of Pharmacy, Yangon, Myanmar; \\ ${ }^{3}$ Department of Pathology, Nagasaki University Graduate School of Biomedical Sciences, Nagasaki, Japan; ${ }^{4}$ Department of Pathology, Kameda \\ Medical Center, Kamogawa, Chiba, Japan \\ Contributions: (I) Conception and design: A Bychkov; (II) Administrative support: A Bychkov, J Fukuoka; (III) Provision of study materials or patients: \\ ZP Oo, AM Hlaing, KCS Kyi; (IV) Collection and assembly of data: ZP Oo, AM Hlaing, KCS Kyi; (V) Data analysis and interpretation: ZP Oo, \\ KCS Kyi, A Bychkov; (VI) Manuscript writing: All authors; (VII) Final approval of manuscript: All authors. \\ Correspondence to: Andrey Bychkov, MD, PhD. Department of Pathology, Kameda Medical Center, 929 Higashi-cho, Kamogawa City, Chiba 296- \\ 8602, Japan. Email: bychkov.andrey@kameda.jp.
}

\begin{abstract}
Fine-needle aspiration cytology (FNAC) of the thyroid is a widely accepted method for aiding the diagnosis of thyroid nodules. In Myanmar, it has been done since the early 1990s, and mainly performed by surgeons and otorhinolaryngologists. The interpretation of cytology is solely made by pathologists. Although some of the experts particularly those from specialist hospitals use the Bethesda System for Reporting Thyroid Cytopathology (TBSRTC), many still prefer the British five-tier cytopathology report. Available local publications addressing the accuracy of FNAC and cytologic-histologic correlations were queried. Ten studies performed in 1991-2018 on 540 thyroid nodules were included. Cytologic-histologic correlations showed a range of sensitivity from $64.29 \%$ to $100 \%$, specificity from $93 \%$ to $100 \%$, and diagnostic accuracy from $94 \%$ to $100 \%$. The adoption of TBSRTC by pathologists is still slow and should be encouraged via seminars and training programs. Further multihospital-based large cohort studies with uniform design and adequate follow-up are needed to better promote and assess utility of thyroid FNAC in Myanmar.
\end{abstract}

Keywords: Fine-needle aspiration cytology (FNAC); Myanmar; the Bethesda System for Reporting Thyroid Cytopathology; thyroid

Submitted Mar 27, 2020. Accepted for publication May 13, 2020.

doi: $10.21037 / g s-20-414$

View this article at: http://dx.doi.org/10.21037/gs-20-414

\section{Background}

Myanmar, formerly known as Burma, is a country located in Southeast Asia bordered by China, India, Bangladesh, Laos and Thailand, with the population over 53 million (1). The majority of the population (around $70 \%$ ) lives in rural areas and being a country with hilly regions and delta regions where iodine content of the soil is deficient, thyroid disorders are commonly seen in the daily practice of a general practitioner. Although the incidence of goiter has been declined after implementation of universal salt iodization program, a spectrum of thyroid diseases ranged from hypothyroidism to multinodular goiter and thyroid cancer is still commonly encountered. Moreover, follicular cancers predominate in iodine-deficient population and papillary cancers predominate in iodine-replete population (2).

Thyroid carcinoma is the fifth most common malignancy in women worldwide with the global incidence of $5.5 \%$ (3). Thyroid cancer incidence rates are 3 times higher in women than in men (21 vs. 7 per 100,000 population), despite equivalent death rates ( 0.5 per 100,000 population) (4). The

^ ORCID: Zun Pwint Oo, 0000-0003-4968-2236; Aung Myo Hlaing, 0000-0002-5311-1412; Khin Chaw Su Kyi, 0000-0002-5652-3471; Junya Fukuoka, 0000-0002-2496-3050; Andrey Bychkov, 0000-0002-4203-5696. 
incidence of thyroid cancer in Myanmar women is 3.8 per 100,000 population (5), which is lower than in Thailand bordering from the east $(5.1 / 100,000)(6)$. Furthermore, the incidence of thyroid cancer among goitrous thyroid cases in Myanmar was higher compared to close neighbor Malaysia which may be due to the higher prevalence of long-standing untreated goiter (7).

Thyroid fine-needle aspiration cytology (FNAC) was introduced in the 1950s and became popular worldwide in the 1980s. Today, it is a well-established technique for preoperative diagnosis of thyroid nodules. FNAC has been proven to be an important, simple, safe and first-line investigation in the evaluation of various thyroid lesions. Most of the knowledge about thyroid FNA is based on Western studies and guidelines $(8,9)$. However, it has been known that nearly half of the new thyroid cancer cases are originated from Asia, the largest world continent with the diversity in ethnicity, lifestyle and health care systems (10). Numerous publications elucidated considerable differences between Western and Asian series of thyroid cancerfrom biology and epidemiology to practice patterns and treatment strategies (11-14). Such differences are also seen in cytopathology practice and touch upon sampling approaches, preparation techniques, and reporting systems, also prevalence, resection rate and risk of malignancy (ROM) for each diagnostic category (15-17). Therefore, local experience from each Asian country should be regarded accordingly in order to tailor the national guidelines compatible with the characteristics of the health care system.

This article represents an overview of the thyroid FNA contemporary practice in Myanmar by interviewing the pathologists from major cities of all fourteen states and regions of Myanmar and supplemented by available theses and dissertations from the five medical universities.

\section{Historical and technical aspects}

FNA of the thyroid was started in Myanmar in the early 1990s and was initially performed by surgeons. Later on, otorhinolaryngologists have started operating FNA. From the beginning till now, the interpretation of FNAC is solely done by pathologists since there are no cytotechnologists in Myanmar. Moreover, none of the clinicians diagnose FNAs by themselves.

In major cities, the FNA procedure is usually performed by otorhinolaryngologists and sometimes by surgeons. Ultrasound-guided FNA sampling is used occasionally, for example at specialist hospitals and private hospitals. In many regional hospitals which lack otorhinolaryngologists and surgeons, residents and general practitioners are responsible for performing thyroid FNA. Physicians and radiologists rarely perform FNA. Only a few pathologists who have a special interest in the cytology perform FNA by themselves but onsite evaluation is not provided.

Most operators perform FNA by using a $10 \mathrm{~mL}$ syringe with 23 or 24 gauge needle without a syringe holder. Some doctors prefer fine needle non-aspiration cytology (FNnAC) method which is believed to give superior quality smear by minimizing bloody aspirates. The FNAC procedure starts with sterile precautions, localization of the lesion by palpation and immobilization by grasping the nodule with two fingers of one hand followed by insertion of a needle into the lesion with gentle suction and, moving back and forth for 5 passes at the two different directions. Once the aspirate appears, the needle is taken out. The FNnAC procedure is the same apart from that only needle without syringe or suction is used during aspiration.

After placing a small drop of the aspirated material onto several glass slides, the smears are made by using a second glass slide exerting a light pressure to achieve a thin, even spread, in a manner similar to that of making blood smears. Most of the clinicians submit air-dried smears to the laboratories. Air-dried samples are usually stained with Diff-Quik method based on Romanowsky-Giemsa stain. Hematoxylin and eosin stain is still used in some laboratories because it is cheaper and widely available. Only a few laboratories use conventional Papanicolaou stain particularly when the aspiration is done by pathologist so that wet fixation can be done. To our knowledge, liquidbased preparation for thyroid FNA cytology is not used in Myanmar.

Ancillary studies of thyroid FNA such as immunocytochemistry and molecular testing have not been introduced in the country. Even for the surgical specimens of the thyroid, immunohistochemistry is rarely used. The same holds true for molecular testing - there are some academic research projects investigating $B R A F$ mutation in thyroid cancer which are carried out in surgical specimens. However, implementation of the molecular testing for routine use is still a challenge because of the cost and limited facilities.

\section{Thyroid cytology reporting system}

There is no standard format for reporting thyroid FNA 
Table 1 Reclassification of cases according to corresponding TBSRTC categories

\begin{tabular}{ll}
\hline Bethesda category & Different classifications used in the local studies \\
\hline I & Unsatisfactory, no thyroid follicular cells (C0); <6 groups of follicular cells (C1) \\
II & $\begin{array}{l}\text { Absence of atypical cells (type I); malignant cells not present, benign (C2); atypical cytology but no evidence of } \\
\text { malignancy (type II) }\end{array}$ \\
III & - \\
IV & Follicular aspirate, equivocal-hyperplastic nodule vs. follicular neoplasm (C3) \\
V & $\begin{array}{l}\text { Suggestive of, but not conclusive for malignancy (type III); cytology strongly suggestive of malignancy (type IV); } \\
\text { Suspicious of malignancy (C4) }\end{array}$ \\
VI & Cytology conclusive for malignancy (type V); malignant (C5)
\end{tabular}

TBSRTC, the Bethesda System for Reporting Thyroid Cytopathology.

used by all pathologists across Myanmar. The Bethesda System for Reporting Thyroid Cytopathology (TBSRTC) which is the current standard reporting system worldwide, has been released and promoted since $2009(8,9)$. However, only some of the pathologists mostly from Yangon, the largest city of Myanmar, seem to adapt to this system. A majority of pathologists still prefer reporting definitions of the 5-tiered British system (RCPath 2009) (18). This may be due to tight historical links considering that many senior pathologists received training from the UK in the past. However, upon interviewing otorhinolaryngologists, it was found that the reported FNAC results are converted to the closest TBSRTC categories since the clinicians follow the treatment guidelines according to TBSRTC system. We may conclude that among the pathologists' community, the transition of reporting system from the 5-tier RCPath to six-tier TBSRTC is slow.

In Myanmar, private laboratories are widely established, and the clinicians tend to send samples to different labs. Furthermore, patients tend to seek medical services in different hospitals. Therefore, it is not uncommon that FNAC smears and surgical specimens end up in different laboratories. In such cases, comparison of FNAC result with histopathology is an unlikely task. However, all thyroid surgeries with previous FNA done at the same hospital are reviewed. Apart from that, there is no external audit program for now.

\section{Review of publications}

In Myanmar, most of the studies on thyroid cytology were theses and dissertations which were hospital-based and done at the tertiary teaching hospitals and specialist hospitals from three major cities (Yangon, Mandalay, and
Magway) where medical universities are located. Although PubMed and Google Scholar were searched for keywords "Myanmar", "thyroid", "FNA", and "cytology", no publication on thyroid FNA in international journals was found.

There were 10 available theses and dissertations from the libraries of five medical universities dated 1992-2018 (19-28). These studies were mainly focused on cytologichistologic correlations and analytical performance of the method. Comparisons between FNAC and FNnAC techniques were also studied.

The terminology of TBSRTC was not uniformly used in local settings and most of the studies were performed before 2009. Some older studies used the universal Papanicolaou classification while others subcategorized the follicular aspirates after knowing the fact that follicular adenoma and carcinoma cannot be differentiated based on aspirations. Only one recent study used TBSRTC (27). Therefore, we converted the cytologic diagnoses to the closest Bethesda system categories, as shown in Table 1 .

The summary of available publications is presented in Table 2. Cytologic-histologic correlation yielded a range of sensitivity from $64.3 \%$ to $100 \%$, specificity from $93 \%$ to $100 \%$, and accuracy from $94 \%$ to $100 \%$. It should be noted that all of these studies only included cases that underwent operation, which would create bias and the actual proportion of each cytological category along with resection rates could not be assessed. In addition, study designs were heterogeneous and, to our knowledge, there is still no welldesigned study on this topic to date.

Ten studies performed in 1991-2018 enrolled 540 nodules in total (19-28). The vast majority of aspirates (72\%) were benign (Table 2). Malignant and suspicious for malignancy nodules constituted collectively $13.9 \%$. 
Table 2 Summary of the studies on thyroid FNA in Myanmar

\begin{tabular}{|c|c|c|c|c|c|c|c|c|c|c|c|c|}
\hline \multirow{2}{*}{ Author } & \multirow{2}{*}{ Year } & \multirow{2}{*}{ Hospital } & \multirow{2}{*}{ Patients } & \multicolumn{6}{|c|}{ Distribution by the Bethesda categories (\%) } & \multirow{2}{*}{$\begin{array}{c}\text { Sensitivity, } \\
\%\end{array}$} & \multirow{2}{*}{$\begin{array}{c}\text { Specificity, } \\
\%\end{array}$} & \multirow{2}{*}{$\begin{array}{c}\text { Accuracy } \\
\%\end{array}$} \\
\hline & & & & I & II & III & IV & V & VI & & & \\
\hline PM Swe (19) & 1991-1992 & YGH, NYGH & 25 & $1(4 \%)$ & $20(80 \%)$ & - & - & $4(16 \%)$ & - & 100 & 100 & 100 \\
\hline H Oo (20) & $1993-1994$ & $\mathrm{MGH}$ & 36 & $3(8.33 \%)$ & $27(75 \%)$ & - & - & $2(5.5 \%)$ & $4(11.1 \%)$ & 80 & 100 & 97.5 \\
\hline M Maw (21) & $1996-1997$ & YGH, NYGH & 39 & $6(15.4 \%)$ & $17(43.5 \%)$ & - & $14(35.9 \%)$ & $1(2.6 \%)$ & $1(2.6 \%)$ & 100 & 100 & 100 \\
\hline T Oo (22) & $1997-1998$ & NOGH, DSGH & 32 & $3(9.3 \%)$ & $25(78.1 \%)$ & - & - & $2(6.3 \%)$ & $2(6.3 \%)$ & 75 & 100 & 96 \\
\hline KK Tun (23) & 2003-2004 & EENT-Mdy, MGH & 50 & $4(8 \%)$ & $33(66 \%)$ & - & $4(8 \%)$ & $4(8 \%)$ & $5(10 \%)$ & 83.3 & 100 & 98 \\
\hline T Soe (24) & 2005-2006 & ORL-HNS & 50 & 0 & $35(70 \%)$ & - & - & $4(8 \%)$ & $11(22 \%)$ & 93 & 94.4 & 94 \\
\hline A Myat (25) & 2006-2007 & YGH, NYGH & 34 & $1(2.9 \%)$ & $29(85.3 \%)$ & - & - & $3(8.9 \%)$ & $1(2.9 \%)$ & 100 & 100 & 100 \\
\hline KS Tun (26) & 2009-2010 & EENT-Mdy & 22 & - & $13(59.1 \%)$ & - & $2(9.1 \%)$ & - & $7(31.8 \%)$ & 100 & 93 & 95 \\
\hline HL Aung (27) & 2015-2017 & ORL-HNS & 170 & $2(1.2 \%)$ & $137(80.6 \%)$ & $5(2.9 \%)$ & $8(4.7 \%)$ & $9(5.3 \%)$ & $9(5.3 \%)$ & 64.3 & 100 & 94.1 \\
\hline CNW Lwin (28) & 2017-2018 & MTH, MRH & 82 & $20(24.3 \%)$ & 56 (68.3\%) & - & - & $3(3.7 \%)$ & $3(3.7 \%)$ & 100 & 100 & 100 \\
\hline
\end{tabular}

FNA, fine-needle aspiration; YGH, Yangon General Hospital; NYGH, New Yangon General Hospital; MGH, Mandalay General Hospital; NOGH, North Okkalapa General Hospital; DSGH, Defence Services General Hospital; EENT-Mdy, Eye, Ear, Nose and Throat Hospital, Mandalay; ORL-HNS, Otorhinolaryngology Head \& Neck Surgery Specialist Hospital; MTH, Magway Teaching Hospital; MRH, Magway Regional Hospital.

Table 3 Comparison of FNAC results and histopathology results in two most recent studies $(27,28)$

\begin{tabular}{lccc}
\hline TBSRTC & Total nodules, $\mathrm{n}(\%)$ & ROM & Implied ROM (9) \\
\hline I & $22(8.7 \%)$ & $1 / 22(4.5 \%)$ & $5-10 \%$ \\
II & $193(76.6 \%)$ & $2 / 193(1 \%)$ & $0-3 \%$ \\
III & $5(2 \%)$ & $4 / 5(80 \%)$ & $10-30 \%$ \\
IV & $8(3.2 \%)$ & $3 / 8(37.5 \%)$ & $25-40 \%$ \\
V & $12(4.8 \%)$ & $12 / 12(100 \%)$ & $50-75 \%$ \\
VI & $12(4.8 \%)$ & $12 / 12(100 \%)$ & $97-99 \%$ \\
Total & 252 & $34 / 252(13.5 \%)$ & \\
\hline
\end{tabular}

FNAC, fine-needle aspiration cytology; TBSRTC, the Bethesda system for reporting thyroid cytopathology; ROM, risk of malignancy.

The nondiagnostic rate was low (7.4\%). Considering the limitations outlined above, such as marked heterogeneity with terminology and study design, we performed a further analysis in a subgroup of the most recent studies $(27,28)$ (Table 3). ROM for the diagnostic categories was basically within the limits implied by TBSRTC. The only marked deviation was noted for category III, which showed $80 \%$ ROM instead of $10-30 \%$ range suggested by the Bethesda system. Unfortunately, none of the original studies provided cytologic-histologic correlations on a case basis, therefore we were not able to investigate the nature of such discrepancy. Neither could we access additional TBSRTC outputs, including resection rate per each category, risk of neoplasia, and overall ROM.

It is intuitive that at the current stage of economic development, Myanmar health care system cannot qualify to the standards of well-developed countries. Therefore, in addition to matching our data on thyroid cytology with Western experience, as described above, we also compared local findings with reports from the neighboring countries. Publications on thyroid FNA from Southeast Asia are scarce and non-systematic (15). An institutional experience with FNAC could be occasionally found in the local journals of the neighboring countries, including Thailand, Bangladesh, Nepal, and others (29-31). However, we were able to access review articles on thyroid cytology covering all the aspect of 
this topic only from Thailand and the Philippines $(32,33)$.

Compared to Myanmar, pathologists from Thailand and the Philippines were more adapted to TBSRTC reporting system, which was credited in the national guidelines in Thailand $(32,33)$. Furthermore, there were cytopathologists who had studied abroad for fellowship and such trainings were recognized by the local pathology society. Although the Philippines did not set up external quality assurance program like Myanmar, Thailand has already set up such program which issues certificates upon completion.

\section{Current limitations and perspectives}

In Myanmar, hospital-based data for cytologic-histologic correlation are still lacking not only because of the samples being sent to different laboratories and highly mobile patients but also due to the technical limitations. These issues can be solved by establishing a national registry participated by both private and government hospitals. The Ministry of Health has been trying to do so but financial and technical difficulties are yet to overcome. Multihospitalbased large studies on thyroid cytology with a uniform design and adequate follow-up are needed to conduct on the national level.

Another matter is pathologists from Myanmar are trained to be general pathologists because of the shortage of manpower. Just recently, starting from 2019, the training period for the pathologist has been changed from two years to three years, during which the trainees have to do rotations in histopathology, hematopathology, clinical biochemistry, and microbiology sections at the teaching hospitals. Cytopathology is included as a part of the histopathology rotation. The competency is determined by the dissertations, written exams, practical exams, and viva voce. After that, the fresh graduates have to practice at the teaching hospitals for at least one year before starting to work independently at the district hospitals. Myanmar pathologists have to practice not only anatomic pathology but also hematopathology, blood transfusion, chemical pathology and even microbiology in some hospitals which lack microbiologists. Therefore, practicing subspecialty and becoming a cytopathologist is difficult to accomplish. Nonetheless, with the increase in the number of pathologists during recent years, subspecialty training and practicing should be established.

Being a developing country with ongoing political and economic reforms, continuous training of practicing pathologists from different parts of the country for all subspecialties is still a big challenge. But in the internet era, it may be more beneficial if the up-to-date knowledge is shared through easily accessible websites and social media where mandatory webinars and seminars should be implemented to distribute knowledge. Furthermore, long term training projects in foreign countries and more manpower are necessary for pathologists to practice subspecialty and cytopathology.

The Myanmar Society of Pathology is currently putting efforts to provide continuing medical education for all members. Noninvasive follicular thyroid neoplasm with papillary-like nuclear features (NIFTP) is a good example of how efficiently new knowledge could be spread in the community. While this new entity has been introduced very recently (34), it was comprehensively discussed during the annual meeting with the invitation of international faculty. As a result, surgical pathologists and clinicians use NIFTP terminology in daily practice. Similar to the other Asian countries $(14,34)$, NIFTP diagnosis is very rarely encountered in Myanmar.

\section{Conclusions}

This is the first and only contemporary report on thyroid FNA in Myanmar available to international audience. Previous local studies concluded that FNAC was a reliable diagnostic method for thyroid nodules reaching 94-100\% accuracy. Although TBSRTC was not used apart from one recent study, ROM for the adjusted diagnostic categories was basically within the limits implied by TBSRTC, except category III showing markedly increased malignancy rate. The adoption of TBSRTC by pathologists is still slow and should be encouraged via seminars and training programs. Further multihospital-based large cohort studies with uniform design and adequate follow-up are needed to better promote and assess utility of thyroid FNAC in Myanmar.

\section{Acknowledgments}

We express our gratitude to the pathologists and clinicians from various states and regions of Myanmar for responding the survey on FNA practice in Myanmar.

Funding: None.

\section{Footnote}

Provenance and Peer Review: This article was commissioned by the Guest Editor (Kennichi Kakudo) for the series "Asian 
and Western Practice in Thyroid Pathology: Similarities and Differences" published in Gland Surgery. The article was sent for external peer review organized by the Guest Editor and the editorial office.

Conflicts of Interest: All authors have completed the ICMJE uniform disclosure form (available at http:// dx.doi.org/10.21037/gs-20-414). The series "Asian and Western Practice in Thyroid Pathology: Similarities and Differences" was commissioned by the editorial office without any funding or sponsorship. The authors have no other conflicts of interest to declare.

Ethical Statement: The authors are accountable for all aspects of the work in ensuring that questions related to the accuracy or integrity of any part of the work are appropriately investigated and resolved.

Open Access Statement: This is an Open Access article distributed in accordance with the Creative Commons Attribution-NonCommercial-NoDerivs 4.0 International License (CC BY-NC-ND 4.0), which permits the noncommercial replication and distribution of the article with the strict proviso that no changes or edits are made and the original work is properly cited (including links to both the formal publication through the relevant DOI and the license). See: https://creativecommons.org/licenses/by-nc-nd/4.0/.

\section{References}

1. Central Statistical Organization. Statistics overview of Myanmar Population [Internet] 2018 [cited 2020 Feb 12]. Available online: https://www.csostat.gov.mm

2. Htwe TT, Ko M. Thyroid Cancers: A Three Years Retrospective Histopathological Study. J Myan Acad Tech 2001;1:23-30.

3. Bray F, Ferlay J, Soerjomataram I, et al. Global cancer statistics 2018: GLOBOCAN estimates of incidence and mortality worldwide for 36 cancers in 185 countries. CA Cancer J Clin 2018;68:394-424.

4. Siegel RL, Miller KD, Jemal A. Cancer Statistics, 2017. CA Cancer J Clin 2017;67:7-30.

5. International Agency for Research on Cancer. Estimated number of incident cases Myanmar, females, all ages [Internet] 2020 (accessed 23.01.2020). Available online: https://bit.ly/2TA7L2d

6. Tangjaturonrasme N, Vatanasapt P, Bychkov A. Epidemiology of head and neck cancer in Thailand. Asia
Pac J Clin Oncol 2018;14:16-22.

7. Htwe TT. Thyroid malignancy among Goitrous thyroid lesions: A review of hospital-based studies in Malaysia and Myanmar. Singapore Med J 2012;53:159-63.

8. Cibas ES, Ali SZ. The Bethesda System for Reporting Thyroid Cytopathology. Thyroid 2009;19:1159-65.

9. Cibas ES, Ali SZ. The 2017 Bethesda System for Reporting Thyroid Cytopathology. Thyroid 2017;27:1341-6.

10. Kakudo K, Bychkov A, Bai Y, et al. The new 4th edition World Health Organization classification for thyroid tumors, Asian perspectives. Pathol Int 2018;68:641-64.

11. Kakudo K, Bychkov A, Abelardo A, et al. Malpractice climate is a key difference in thyroid pathology practice between North America and the rest of the world. Arch Pathol Lab Med 2019;143:1171.

12. Kakudo K, Higuchi M, Hirokawa M, et al. Thyroid FNA cytology in Asian practice-Active surveillance for indeterminate thyroid nodules reduces overtreatment of thyroid carcinomas. Cytopathology 2017;28:455-66.

13. Bychkov A. Prevalence of BRAFV600E mutation in Asian patients with thyroid cancer. Malays J Pathol 2017;39:95-6.

14. Bychkov A, Hirokawa M, Jung CK, et al. Low Rate of Noninvasive Follicular Thyroid Neoplasm with PapillaryLike Nuclear Features in Asian Practice. Thyroid 2017;27:983-4.

15. Bychkov A, Kakudo K, Hong SW. Current practices of thyroid fine-needle aspiration in Asia: A missing voice. J Pathol Transl Med 2017;51:517-20.

16. Jung CK, Hong SW, Bychkov A, et al. The use of FineNeedle Aspiration (FNA) cytology in patients with thyroid nodules in Asia: A brief overview of studies from the working group of Asian Thyroid FNA Cytology. J Pathol Transl Med 2017;51:571-8.

17. Vuong HG, Ngo HTT, Bychkov A, et al. Differences in surgical resection rate and risk of malignancy in thyroid cytopathology practice between Western and Asian countries: A systematic review and meta-analysis. Cancer Cytopathol 2020;128:238-49.

18. Poller DN, Baloch ZW, Fadda G, et al. Thyroid FNA: New classifications and new interpretations. Cancer Cytopathol 2016;124:457-66.

19. Swe PM. Evaluation of fine needle aspiration cytology in breast lump and clinically solitary thyroid nodule. M.Med. Sc (Surgery). Yangon, the Republic of the Union of Myanmar, University of Medicine 1; 1992.

20. Oo H. Role of fine needle aspiration cytology in management of solitary thyroid nodules. M.Med. 
Sc (Surgery). Mandalay, the Republic of the Union of Myanmar, University of Medicine, Mandalay; 1994.

21. Maw M. Study of value of fine needle aspiration cytology in the solitary thyroid nodule. M.Med.Sc (Surgery). Yangon, the Republic of the Union of Myanmar, University of Medicine 1; 1997.

22. Oo T. Fine needle aspiration cytology in nodular thyroid swellings. M.Med.Sc (Surgery). Yangon, the Republic of the Union of Myanmar, University of Medicine 2; 1998.

23. Tun KK. A comparative study of fine needle aspiration cytology and biopsy in the diagnosis of thyroid swellings. M.Med.Sc (Pathology). Mandalay, The Republic of the Union of Myanmar, University of Medicine, Mandalay; 2005.

24. Soe T. A study of validity of ultrasound-guided fine needle aspiration cytology (FNAC) in solitary thyroid nodules at E.N.T. Hospital Yangon. M.Med.Sc (Otorhinolaryngology). Yangon, the Republic of the Union of Myanmar, University of Medicine 1; 2006.

25. Myat A. Study of value of non-aspiration fine needle cytology in solitary thyroid nodules. M.Med.Sc (Surgery). Yangon, the Republic of the Union of Myanmar, University of Medicine 1; 2007.

26. Tun KS. Diagnostic value of fine needle non-aspiration cytology in solitary thyroid nodules. M.Med.Sc (Pathology). Mandalay, the Republic of the Union of Myanmar, University of Medicine, Mandalay; 2011.

27. Aung HL. Accuracy of ultrasound-guided fine needle aspiration cytology in thyroidectomy patients. M.Med.Sc (Otorhinolaryngology-Head and Neck Surgery). Yangon,

Cite this article as: Oo ZP, Hlaing AM, Kyi KCS, Fukuoka J, Bychkov A. An overview of thyroid fine-needle aspiration practice in Myanmar. Gland Surg 2020;9(5):1747-1753. doi: 10.21037 /gs-20-414 the Republic of the Union of Myanmar, University of Medicine 1; 2017.

28. Lwin CNW. Diagnostic utility of fine needle nonaspiration and aspiration cytology techniques in thyroid nodules. M.Med.Sc (Pathology). Magway, the Republic of the Union of Myanmar, University of Medicine, Magway; 2018.

29. Limlunjakorn P, Keelawat S, Bychkov A. Evaluation of thyroid fine needle aspiration cytology by the Bethesda reporting system: A retrospective analysis of rates and outcomes from the King Chulalongkorn Memorial Hospital. J Med Assoc Thail 2017;100:783-92.

30. Choudhary P, Nepal N, Mainali N, et al. Implementation of Bethesda system in thyroid aspirate: A cytohistopathological correlation study. J Pathol Nepal 2016;6:902-5.

31. Hassan MQ, Hasanat MA, Fariduddin M, et al. Fine needle aspiration cytological diagnosis of thyroid nodule with its clinical correlation. Bangabandhu Sheikh Mujib Med Univ J 2016;6:108.

32. Keelawat S, Rangdaeng S, Koonmee S, et al. Current status of thyroid fine-needle aspiration practice in Thailand. J Pathol Transl Med 2017;51:565-70.

33. Abelardo AD. Thyroid fine-needle aspiration practice in the Philippines. J Pathol Transl Med 2017;51:555-9.

34. Bychkov A, Jung CK, Liu Z, et al. Noninvasive Follicular Thyroid Neoplasm with Papillary-Like Nuclear Features in Asian Practice: Perspectives for Surgical Pathology and Cytopathology. Endocr Pathol 2018;29:276-88. 